tions than for the same current in stronger solutions, up to 30 per cent. This shows itself especially with thin plates, and also in the shorter time required for thick plates to reach a maximum polarization with weak currents. The greater change in temperature and the greater change in concentration of weak solutions may account for this.

For currents between 0.1 and 0.2 ampere, the polarization on the end electrodes was:-

For $\mathrm{H}_{2} \mathrm{SO}_{4}, 1.84$;

" NaCl, 1.98;

" $\mathrm{CuSO}_{4}, 0.00$, with $\mathrm{Cu}$ electrodes, though, if the current density was too great or the time long, the anode would oxidize and become irregular. C. Fromme, in a paper, "Ueber das Maximum der galvanischen Polarisation von Platinelektroden in Schwef elsäure" (Annalen d. Physik u. Chemie, Band XXXIII., s. 80-126), states that the maximum polarization varies both with the concentration and the relative size of the electrodes, the extreme limits being given as 1.45 to 4.31 volts - the minimum polarization coinciding with maximum conductivity. His method for measuring polarization was somewhat similar to that used in this work. As bearing upon "the change of polarization with time," I would refer especially to the investigation of Dr. E. Root upon this subject, discussed by Professor von Helmholtz, Wisch. Abh., Vol.I., page 835. These experiments by Dr. Root seem to prove clearly that the liberated ions penetrate deeply into the electrode, even when liberated upon but one side of it, as in this case. I take great pleasure in expressing here my thanks and deep obligation to Professor A. Kundt and Dr. L. Arons for their kind sympathy and direction in this work.

Using $\mathrm{CuSO}_{4}$ on one side of the partition, and $\mathrm{H}_{2} \mathrm{SO}_{4}$ on the other side, careful determinations have developed the curious fact that, although there is no visible development of ions (neither $\mathrm{Cu}$ nor $\mathrm{O}$ ) at the gold-leaf partition, yet the $\mathrm{Cu}$ does not pass through the gold-leaf with the current, but $\mathrm{H}$ appears on the cathode instead, provided the current density at the partition be not greater than about .2 ampere per square centimetre.

The "critical current-density" at which the ions just begin to appear visibly on a gold-leaf partition varies for different electrolytes between the limit of 5.7 amperes for 30 per cent $\mathrm{H}_{2} \mathrm{SO}_{4}$ and :sensibly zero for lead acetate.

This "critical current-density" is proportioned to the conductivity of the electrolyte. It therefore also bas a decided positive temperature co-efficient.

\section{ON THE FORMATION OF ALUMINUM SULPHATE IN THE SHALES THROWN FROM COAL-MINES.}

BY M. H. LOCKWOOD, ASSISTANT IN THE DEPARTMENT OF GEOLOGY AND. MINERALOGY, MISSOURI STATE UNIVERSITY.

My attention was recently called to a white crystaline formation found on and between the lasers of a red-colored shale that is much used for walks in Columbia, Mo., and is obtained from the old waste heaps of coal-mines in the vicinity. Upon examination $I$ found it to consist of aluminum sulphate, which is readily soluble in water, and has an alum-like taste. Occasionally some iron sulphate is present. The question arose as to bow the aluminum sulphate was formed in between, and on, the layers of the shale.

For the purpose of studying the formation, I visited the Reece mine at Henry Station, on the Wabash railroad, and there collected the following waste materials as thrown from the mine, viz., fre-clay taken from below the coal, clay-parting from a layer about six inches from the bottom of the coal seam, iron pyrites mixed with coal from spots throughout the coal seam, clay containing iron pyrites and carbonaceous matter from just above the coal, and a blue argillaceous shale from above the coal.

The waste materials thrown from the mine, and exposed to the air and moisture, go through the process of slacking or burning, and it is during this process that the aluminum sulphate is formed. I also collected specimens from the burned and from the burning heaps about the mine.

Upon examination of the fresh specimens I found that the fireelay contained no free aluminum compound that would form aluminum sulphate after the slacking or oxidation of the heaps. The clay-parting and other specimens containing iron pyrites and carbonaceous matter, will oxidize so rapidly when exposed to the air that the mass takes fire and we have iron sulphate and sulphuric acid formed. The sulphuric acid combines with the aluminum in the shales and clays about it, forming aluminum sulphate which crystalizes on the surface.

The shale from above the coal contains some simple compound of aluminum (probably the hydrate), and a considerable quantity of free sulphur. The presence of the aluminum was shown by the cobalt-nitrate test, and, also, when some of the shale was boiled with hydrochloric acid and filtered, the solution gave a white precipitate of aluminum hydrate upon the addition of ammonium hydrate.

Some pieces of the shale contained so much free sulphur that they would burn, upon ignition, with a blue flame, giving off fumes of sulphur dioxide. When some of the powdered shale was leached with carbon dioxide, and the solution evaporated, a residue of sulphur was obtained. These tests indicate that the sulphur and aluminum thoroughly penetrate the shale. When the heaps burn the sulphur becomes highly oxidized, and combines with the aluminum, forming aluminum sulphate within the shale. Heat drives the aluminum sulphate to the surfaces, hence it will crystalize between the layers and on the surfaces of the shale.

Free sulphur is found deposited in a crust at the top of the burning heaps. This shows that there is an excess of free sulphur in the waste materials.

The red color of the shale is due to the red oxide of iron formed when the water is driven off by the heat.

\section{CURRENT NOTES ON ANTHROPOLOGY. - XXX. \\ [Edited by D. G. Brinton, M.D., LL.D., D.Sc.] \\ Prehistoric Ethnography of Northeastern Africa.}

THERE are two very learned and suggestive articles in the Beiträge zur Assyriologie, Bd. II., Heft II., 1892, which may be combined to present the latest substantial opinions on the relations and sequence of linquistic stocks in the valley of the Nile and the lands adjacent. The one is by Franz Pastorius, on the Hamitic languages of East Africa; the other on the relations of the Semitic and Old Egyptian languages, by Fritz Hommel. In what I present on the latter theme, I have also had the advantage of a paper read before the Oriental Club of Philadelphia, by the able egyptologist, Professor W. Max Müller.

Scarcely any question in early ethnography could be more important. It touches directly on the origin of the two oldest eivilizations of the world, - the Egyptian and the Babylonian. According to Hommel, the Old Egyptian of the Pyramid Texts, and the Old Babylonian (Semitic) tongues agree so closely in grammar, in sequence of words, in phonetics, and in lexicography, that their near relationship or their common origin must be admitted. Professor Müller informs me that in the Egyptian of the Rammesside epoch at least sixty per cent of the words in use were clearly Semitic. These relations are, however, distinctly not with the western Semites, but directly between the eastern Semitic (Babylonian) and the Old Egyptian. Hommel very pertinently adds that this by no means justifies the conclusion that the original home, die ursprüngliche Heimat, of the common stock was in the valley of the Euphrates; it might just as well have been on the Nile.

Some strength is given to the latter possibility by his comparisons of the Old Egyptian with the Berber dialects. He finds that the lexicon of these latter is Old Lybian, but that their grammar and syntax are very closely related to the Old Egyptian. There is no doubt but that the characteristic forms of the perfect and imperfect tenses were at one time common to the Berber, the Old Egyptian and the Semitic tongues. Besides these, as pointed out by Pastorius, the Hamitic (or Berber) dialects had in common with the original Semitic the personal pronouns, the feminine in $t$, and a number of minor structural elements. He is convinced that the East African Hamites (sometimes called Kushites) have been dwellers on the upper tributaries of the Nile, in Abyssinia, for many thousand years. Of their dialects, 